\title{
BUILDING ON SPRINGS
}

\author{
By R. A. WALLER \\ W. S. Atkins and Partners, Epsom, Surrey
}

A constant source of annoyance that has to be endured by all who live near railways, especially underground railways, is vibration. This is not necessarily so, however, where new lines are being built, or where urban areas are being redeveloped over or alongside railways. Such redevelopment, however, costing each year about $£ 50$ million in Tiondon alone, represents a considerable problem. Recently in London a building was mounted on springs in order to eliminate vibrations generated by a railway and transmitted to it through the ground (see Fig. 1). The design was to be such as to provide an acceptable level of amonity in what were to be high-quality flats. Similar specifications in further buildings could well require that they also be mounted in this way: a method of establishing whether this is worthwhile has been developed ${ }^{1}$.

The problem of mounting a complete building on springs presents the engineer with many interesting and challenging problems. Perhaps the most difficult problems to overcome are the "psychological" ones met in obtaining acceptance for such a scherne. Springs are associated with flexibility and not with the ability to carry load. Now that a precedent has been created it could be that these particular problems will disappear.
When a radical change is made in a well-established form of construction there are likely to be many side effects apart from the obvious problems associated with the design of the springs. The following description will illustrate how many (undoubtedly not all) of these offects and problems were allowed for in the design.

The first step was to define the design requirements, in particular the flexibility required in the springs. This followed from a knowledge of the ambient vibrations in the ground and of the levels of vibration which would be acceptable in the building. The level of vibration in the ground was established by direct moasurement using velocity sensitive probes. The ground vibrated predominantly in the frequency band of $20-25 \mathrm{c} / \mathrm{s}$ although there were some smaller componcnts at lower frequencies (the overall velocity amplitude was about $0.04 \mathrm{in} . / \mathrm{sec}$ ). These readings were taken while the building that was to be demolished to make way for the new one was still intact. The new building is about the same weight as the old and it was considered that the site conditions would not alter significantly or, alternatively, if there was a change, that the predominant frequencies might be somewhat higher because of the reduction in the mass

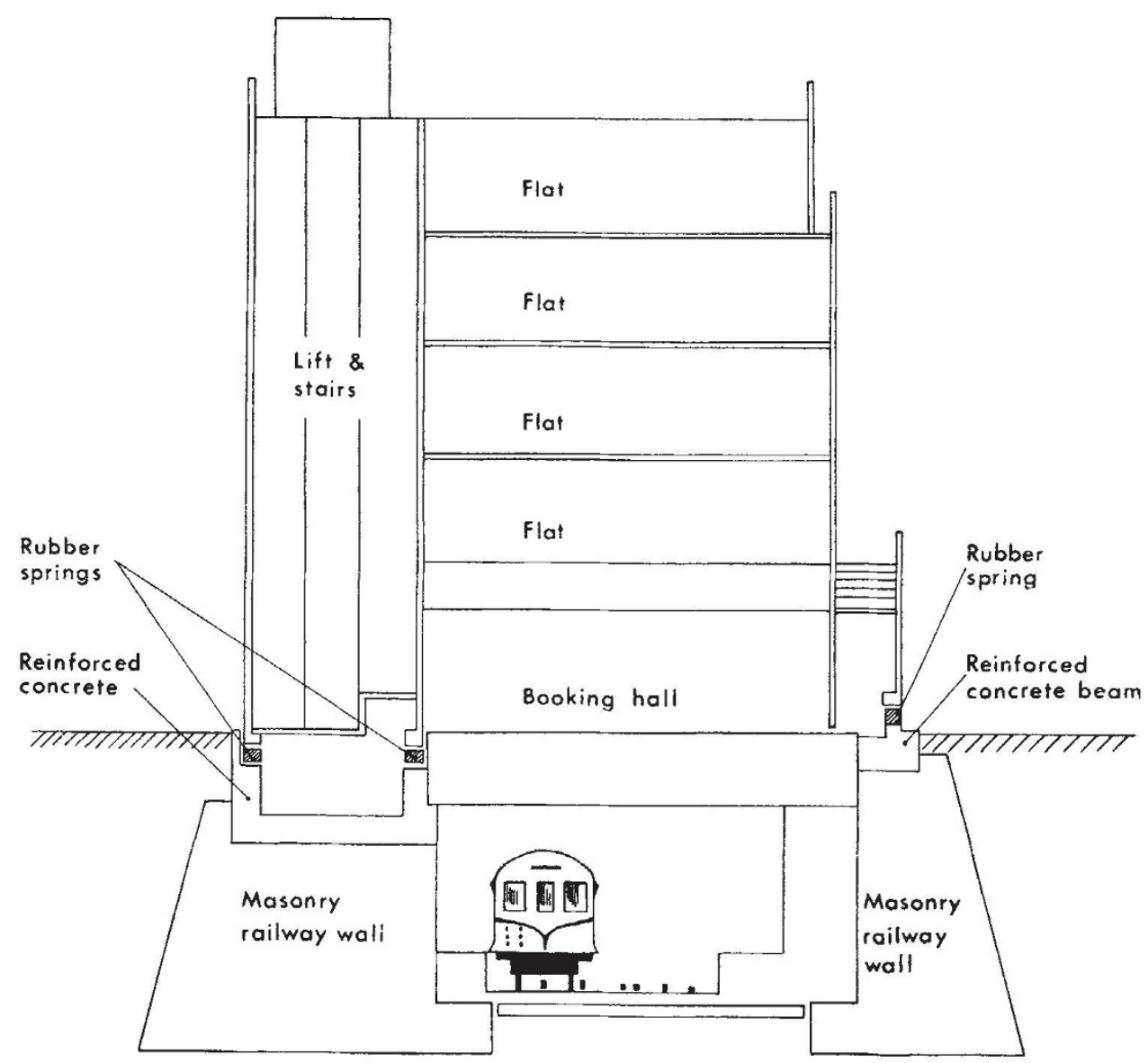

Fig. 1. Cross-section of building on springs 
rigidly connected to the ground. (The only change measured on the completion of the new building was that the lower frequency components were slightly more significant.)

The thresholds of perception of vibration have been widely studied ${ }^{2}$. Experiments have been carried out with people standing, sitting and lying down both parallel and perpendicular to the direction of motion. These have almost all been for sinusoidal single frequency vibration which unfortunately in no way represents the pattern of vibrations produced by the trains. At these low frequencies, however, peak velocity seems to be a reasonable measure of sensitivity and this has been used as the criterion. Owing to the considerable variations in sensitivities from person to person it is not possible to fix a level that would be imperceptible to everybody. As with all engineering problems, it was necessary to compromise and the level was fixed $(0.01 \mathrm{in} . / \mathrm{sec})$ such that only about a sixth of the population could notice the vibrations. The pattern of vibrations generated by the trains consists of a number of peaks superimposed on a background vibration of significantly lower level and the level fixed above was applied to the second highest peak recorded. This was an arbitrary decision made to allow for the transient nature of the vibrations. The difference between the level of the ambient vibration and the level which would be acceptable in the building determined the flexibility required from the springs and the vertical natural frequency of the mounting was fixed at $7 \mathrm{c} / \mathrm{s}$. 'This allowed for the fact that the low frequency components would be magnified.

Apart from the flexibility the other major requirement for the springs was the ability to carry the load of the building. The flexibility and load carrying capacity determined the type of spring which it would be most economic to use. In this case the appropriate type is a laminated rubber spring with steel reinforcing plates ${ }^{3}$. Rubber is elastic but virtually incompressible-its bulk modulus is much the same as that of water. Between two reinforcing plates the rubber tends to flow outwards restrained only by its shear stiffness (Fig. 2). The shear strain is a maximum at the edge of the plates and limits the load that can be applied and the vertical deflexion. The thinner the rubber layer the more able it is to carry vertical load but the stiffer it becomes. In fact it can be shown* that for given load and stiffness requirements the volume of the springs is approximately constant. This is important because it is the volume which, to a first approximation, determines the cost of an individual spring. The engineer has, therefore, a reasonably free hand to determine the proportions he requires for the springs. At one extreme the rubber layers are very thin and numerous but because of the high load carrying capacity the area of the spring is small; at the other extreme the spring has a large area and consists of one single thick layer of rubber.

Generally it will be found best to equate the compressive stress in the springs to that carried in the structure. This provides continuity of load carrying capacity, that is, the

* Note, Design rules (ref. 4) available for similar units used to accommodate expansion movements in bridges give the following criteria for a bonded rubber slab:

$$
\begin{gathered}
f c \text { (the allowable compressive stress) }=\frac{\left(1+2 K S^{2}\right)}{\overline{B S}} \times E \times e s \\
\quad e c \text { (the allowable compressive strain) }=\frac{e s}{6 S}
\end{gathered}
$$

where es is the allowable shear strain (about 150 per cent), $K$ is a constant (about 0.55 ), $E$ is Young's modulus (about $800 \mathrm{lb} . / \mathrm{in} .{ }^{2}$ ), $S$ is the shape factor of the rubber layer $=\frac{\text { area }}{\text { perimeter } \times \text { thickness }}=\frac{w}{4 t}$ for a square layer (about 3 ), $w$ is the width of the layer and $t$ is the thickness of the layer. The volume of
the spring is approximately equal to the area $\times$ total rubber thickness $=\frac{\text { load }}{f c} \times \frac{\text { deflexion }}{e c}$

$$
\begin{aligned}
& =\text { constant } \times \frac{6 S}{\left(1+2 K S^{2}\right) E e s} \times \frac{6 S}{e s} \\
\left(\text { note }\left(1+2 K S^{2}\right) S\right. & \left.={ }_{3} \sim 2 K S^{2}\right) \\
& =\text { constant. }
\end{aligned}
$$

load does not have to be spread unnecessarily from a column in the building to accommodate a spring. In a reinforced concrete building the compressive stress in the columns will generally be $1,000 \mathrm{lb}$./in. ${ }^{2}$ and, as in the present building, there is no difficulty in designing the rubber springs to an identical figure. In steel structures the compressive stresses are higher. While some designs of rubber springs have gone up to 2 tons/in. ${ }^{2}$, and while it is theoretically possible to design springs to match the compressive stress carried by steel (10 tons/in. $\left.{ }^{2}\right)$, it is not at the moment economic to manufacture such springs.

Rubber springs are non-linear their stiffness increases with the speed of loading and their stiffness at small amplitudes is greater than at large amplitudes. Allowance was made for all these factors in the design of the individual springs which entailed a vertical deflexion of $0.4 \mathrm{in}$. Without these effects an ideal linear spring would have required a deflexion of 0.2 in. Rubber has the advantage, however, of providing damping which is useful in causing a rapid decay in any transient disturbance.

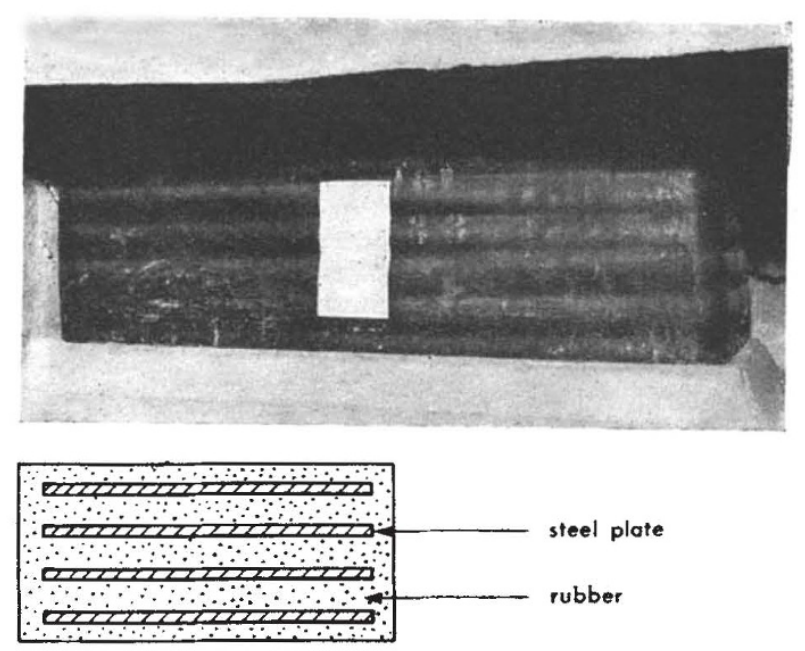

Cross section of bearing

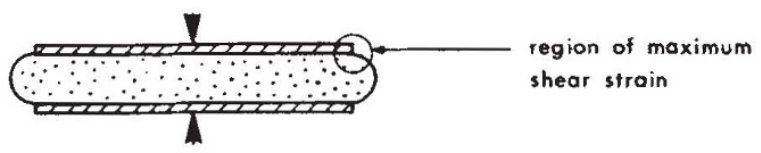

Single rubber layer

Fig. 2. Rubber spring.

It is worth noting in passing that temperature can have a significant effect on the behaviour of rubber although, in the present instance where natural rubber was used, it was of no significance. The flexibility is affected in two ways. There is an instantaneous increase in stiffness as the temperature is lowered; for example, at $-40^{\circ} \mathrm{C}$ natural rubber doubles its stiffness. Secondly, the stiffness inereases gradually with time owing to crystallization at low temperatures; for example, natural rubber begins to crystallize significantly at $-20^{\circ} \mathrm{C}$. The experimental results referred to in Table 1 were all obtained at about the ambient temperature expected in the building.

In the design and manufacture of the group of springs a certain amount of juggling with the sizes was necessary in order to achieve the deflexion requirements with the loads imposed on the springs by the building, and some difficulty was found owing to the degree of non-linearity varying slightly between the different sizes of spring. The biggest spring on the building carried a load of 216 tons and measured 24 in. $\times 20$ in. $\times 11_{16}^{\frac{5}{6}}$ in. 
Table 1. Prophrtifs of the Naturat RUbBer Springs Ratio actual stiffness to stiffness of a linear spring with same deflexion

Ratio dynamic to static stiffness

Ratio stiffness at service amplitudes to stiffness at amplitudo used in dynamic test

$1 \cdot 5-1 \cdot 7$ (measured) 1.14 (measured)

Damping (phase angle)

$1 \cdot 00-1 \cdot 01$ (estimated)

$6^{\circ}$ (measured)

Perhaps the paramount problem in designing springs for incorporation in the foundation of a building is the prediction of their useful life. It is quite possible to jack up a building in order to replace the springs, but this is expensive-probably too expensive. There are three major ways in which the life of a laminated rubber spring could be limited and these were tackled in turn as follows :

(1) Corrosion. The corrosion of the steel reinforcing plates was prevented by embedding them 0.25 in. into the rubber.

(2) Atmospheric attack. Natural rubber is attacked by ultra-violet radiation, oxygen and ozone. Fortunately these are no longer serious problems. The ultra-violet radiation, which might have initiated oxygen attack, is absorbed by the carbon black which is used in the compounding of the rubber. The oxygen attack which results in deterioration of the physical properties of the rubber and the ozone attack which results in the cracking of the rubber where it is strained are both inhibited by the additives used in the manufacture of the rubber. While oxygen and ozone are still, none the less, something of a problem with small sections of rubber (for example, car trims), with the large volumes involved in the springs used here, the main body of rubber is very effectively protected by the outer layers. In particular the critical point at the edge of the bond between the rubber and the steel reinforcing plates is well protected.

(3) Creep. It is difficult to estimate the extent to which rubber springs will creep over long periods of the order of 50 years. There are two mechanisms of creep; one results from the oxygen attack which would occur continuously over the years, but in our present springs this can be discounted because of their size. The more important mechanism is due to the effect of loading which produces a creep of approximately 10 per cent of the initial deflexion every decade, that is, every increase in time by a factor of ten. This can be reduced by overloading the springs before putting them into service. In this case with an initial deflexion of $0.4 \mathrm{in}$. it is estimated that in 50 years the springs might creep a further 0.1 in. from when the building was completed.

It was stated earlier that the introduction of springs into a conventional type of building could have a number of side effects. The effect of rolling a grand piano from one side of the building to the other is fortunately insignificant, but other, perhaps less obvious, effects can cause significant problems. The biggest of these is the effect of wind. Wind loads are not steady and are generated by gusts occurring more or less at random. The problem of wind gusting is one of random vibration and is amenable to some extent to analysis and prediction ${ }^{5}$. Wind gusting can produce significant vibrations in buildings and it is necessary to examine whether the introduction of flexibility into the foundations might aggravate this or introduce the problem where it might not otherwise have existed.

The "size" of a wind gust is fortunately dependent on its frequency, that is, when the structure of the wind is analysed those components which tend to return at high frequency affect a smaller part of the structure than those occurring at low frequencies. It is possible, by making the natural frequency of the structure high enough, for the size of the gusts that would correspond in frequency to be too small to have a significant effect. In this case a horizontal frequency of $2 \frac{1}{2} \mathrm{e} / \mathrm{s}$ was chosen to do just this. As the horizontal frequency of the rubber springs by themselves would have been $\frac{1}{2} \mathrm{c} / \mathrm{s}$ it was neces- sary to provide additional lateral springs. While, from the point of view of wind gusting, a higher frequency still would have further reduced the risk of vibrations generated by wind, a higher frequency would have interfered significantly with the isolation of the vibrations borne through the ground in all directions.

Wind can also generate steady vibrations in a building owing to the shedding of a regular pattern of vortices; this generally occurs with fairly rounded shapes or with sections with extreme shapes such as those approaching the flat plate ${ }^{6}$. In this case, with an approximately square shape and with sharp edges, a steady pattern of vortices is unlikely to be set up. The natural frequency chosen to avoid problems from gusting would, as it happens, also prevent trouble on this score because the vortices cannot be generated at a sufficiently high frequency for the amplitude of vibration to build up.

A small margin of safety was allowed in the springs because the vibrations which were borne through the ground occurred at frequencies which correspond with the range of natural frequencies to be found in building components. So far as possible the floors in particular were designed to have natural frequencies away from the frequencies of vibration occurring in the ground. It is virtually impossible to avoid some magnification. How ever, if severe magnification had occurred, allowance had been made for the construction to be modified and in an extreme case additional damping layers could have been added ${ }^{7}$.

Most buildings have to be designed so that in the event of fire they will not collapse before the occupants have had a reasonable chance to get out. It is probable that the rubber springs would burn slowly because of the protection that would be afforded them by a charred outer layer. It is almost certain that they would continue to support a load longer than the structure itself (in any event, stops were provided to limit the settlement of the building to 0.25 in.).

The construction of the building was straightforward; it was built on the springs; the rate of building was kept uniform and materials were stacked where they were to be used in order to ensure that the load was divided between the springs in accordance with the design. Having introduced springs into the foundation it was essential that nothing "bridged" them; all services, for example, sewers and gas, were provided with flexible connexions. In the same way that, for psychological reasons, the major problem in design was obtaining approval for the scheme in principle, during construction, the major problem was ensuring that the gap under the building was not filled with unwanted material. Workmen are accustomed to plugging such gaps and no matter how often they are told they will probably unconsciously continue to fill any gap that can be filled. As much attention needs to be paid to designing unbridgable gaps as to designing cheap and effective springs.

In spite of all these problems the building was completed. So far nobody sensitive enough to feel any vibrations has been in the building. The economics worked out reasonably well for a difficult site. The cost of the mounting was about 5 per cent (springs alone 2 per cent) of the building costs.

1 Waller, R. A., and Thomas, R. J., The Valuation of Amenity Tech. Commun., W. S. Atkins and Partners, Epsom (1965).

${ }^{2}$ Reiher, H., and Meister, F. J., "The Sensitivity of Human Beings to Vibrations", Forsch. auf dem Geb. des Ing., 2, No. 11; 1931 (in German) also
translated into English by W. S. Atkins and Partners (1965).

"Waller, R. A., "Some Economic Aspects of Anti-Vibration Devices", Symp on "Vibration in Civil Engineering", Imperial College. London, April 1965.

- Ministry of Transport, Provisional Rules for the Use of Rubber Bearings in Highway Bridges, Memo. No. 802 (H.M.S.O., 1962).

Davenport, A. G. " "The Application of Statistical Concepts to Wind Loading of Structures; , Proc. Inst. Civ. Eng., 19, 449 (August 1961).

"Scruton, C., "On the Wind-Excited Oscillations of Stacks, Towers and Masts", Proc. Symp. No. 16, on Wind Effects on Buildings and Structures, Nat. Phys. Lab., June 1963.

${ }^{7}$ Ward, F. L., and Randall, K. E., "Investigation of the Sound Isolation of Concrete Slab Floors," J. Sound Vib., 3 (2), 205 (1966). 